\title{
Strontium and Silicon Co-Doped Apatite Coating: Preparation and Function as Vehicles for Ion Delivery
}

\author{
Carl Lindahl $^{1,2}$, Wei Xia ${ }^{1,2^{*}}$, Jukka Lausmaa ${ }^{2,3}$, Per Borchardt ${ }^{2,3}$, Håkan Engqvist ${ }^{1,2^{*}}$ \\ ${ }^{1}$ Division of Applied Material Science, Department of Engineering Sciences, Uppsala University, Uppsala, Sweden; ${ }^{2}$ BIOMATCELL \\ VINN Excellence Center of Biomaterials and Cell Therapy, Gothenburg, Sweden; ${ }^{3}$ Department of Chemistry and Materials \\ Technology, SP Technical Research Institute of Sweden, Boras, Sweden. \\ Email: $\left\{{ }^{*}\right.$ wei.xia, ${ }^{*}$ hakan.engqvist $\} @$ angstrom.uu.se
}

Received April 2 $2^{\text {nd }}, 2012$; revised May 6 ${ }^{\text {th }}, 2012$; accepted May 26 $6^{\text {th }}, 2012$

\begin{abstract}
New methods to improve the bone response to metallic implants are still emerging, ranging from surface modifications of the metal to coatings and drug delivery. One further development of coatings on implants is to incorporate bioactive ions in order to stimulate the bone response without the need of drug delivery. The aim of the current study is to prepare apatite coatings containing Sr and Si using a solution method, for the purpose of further optimising the bone response to metal implants. Titanium substrates were activated to induce the formation of coatings in modified PBS solutions. Soaking in PBS solutions with different concentrations of strontium and silicate at $37^{\circ} \mathrm{C}$ or $60^{\circ} \mathrm{C}$ produced coatings with different morphologies, thicknesses and compositions. Ion release experiments showed simultaneous release of $\mathrm{Sr}$ and Si from the coatings both in PBS and Tris-HCl. Analysis of the results using the Korsmeyer-Peppas model indicate that the release of ions from the coatings was a combination of Fickian diffusion and dissolution of the coatings. This study shows that it is possible to coat Ti substrates with modified apatite with ion release functionality and thereby increase the possibilities for a tailored bone response in vivo.
\end{abstract}

Keywords: Strontium; Silicon; Apatite Coating; Ion Delivery

\section{Introduction}

Hydroxyapatite (HA) is widely used as a coating to improve the bone-bonding of permanent implants for biomedical applications such as hip prostheses [1,2]. By improving the bond between the implant and bone the risk of revision surgery can be reduced [3,4]. Previously, HA prepared with a mineralization method has been coloaded with bisphosphonates and antibiotics, with the purpose of promoting bone formation around the implant site and reducing the risk of infections [5]. However, the introduction of pharmaceutical agents significantly adds to the complexity of implants, both from a manufacturing, handling and regulatory point of view. Biologically active ions could be used as alternative approach to overcome some of these drawbacks. Studies have shown that ion doped HA, i.e. hydroxyapatite containing foreign ions, is a promising way to improve the cell proliferation and in vivo bone tissue response without the addition of pharmaceutical agents [6-8]. Compared to pure HA, these modified HA have different solubility, crystallinity and topography, all of which are factors that are expected to influence the bone response around the implant [9].

\footnotetext{
${ }^{*}$ Corresponding authors.
}

Bone consists of cells, collagen fibers and hydroxyapatite, the latter containing traces of $\mathrm{Sr}^{2+}, \mathrm{Si}^{4+}$ and $\mathrm{F}^{-}$in the HA-lattice $[10,11]$. Strontium has been shown to enhance the bone formation in vitro and in vivo [12], and the incorporation of silicon into the apatite structure was found to result in a biomaterial with improved osseointegration properties compared to pure hydroxyapatite [6]. A silicon doped hydroxyapatite coating prepared with a mineralization method on porous titanium substrate has also been tested in vivo with promising results [13]. The (in vivo) results showed that the bone ingrowth rate (BIR) was significantly higher for silicondoped HA (Si-HA) coating than for the pure HA [13]. In view of these observations, a simultaneous delivery of multiple ion species from an implant coating in vivo could help to induce bone formation and also reduce bone resorption. It could therefore be possible to combine these effects by co-doping strontium and silicon into the hydroxyapatite coatings. The preparation of co-doped hydroxyapatite ceramics, mostly based on powder techniques, has previously been reported [14-17]. Some work has also been reported on preparation of $\mathrm{Sr}$ or $\mathrm{Si}$ containing hydroxyapatite coatings by a mineralization method [7,18-20]. 
The aim of this work was to prepare apatite coatings containing both $\mathrm{Sr}$ and $\mathrm{Si}$ on pre-treated titanium surfaces for biomedical applications. The coating could act as a system for simultaneous delivery of Sr and Si ions, thus combining the biological effects of these ions. In order to establish process-property relationships, the effects of soaking medium, ion concentration in the soaking medium and soaking temperature on the morphology and composition of the coatings were investigated.

\section{Materials and Methods}

\subsection{Materials}

Titanium plates, size $10 \mathrm{~mm} \times 10 \mathrm{~mm}$, were cut from grade 2, $1 \mathrm{~mm}$ thick sheet of titanium metal (Edstraco $\mathrm{AB}$ Sweden). The plates were oxidized in air at $800^{\circ} \mathrm{C}$ for $1 \mathrm{~h}$ with a ramp rate of $5^{\circ} \mathrm{C} / \mathrm{min}$ to form a titanium dioxide surface. The plates were then treated in an alkaline solution (5 M NaOH) for $1 \mathrm{~h}$ in an ultrasonic bath. Afterwards the plates were ultrasonically treated in successive baths of ethanol (15 $\mathrm{min})$ and water (15 $\mathrm{min})$ at $37^{\circ} \mathrm{C}$ before use.

\subsection{Preparation of Sr and Si Co-Doped Apatite Coatings}

The Sr and Si containing apatite coatings were prepared by a mineralization process. A modified solution of Dulbecco's phosphate buffer saline (PBS, Aldrich) was used as solution medium. Strontium nitrate was used as the source of Sr ions and sodium silicate was used as the $\mathrm{Si}$ ion source. PBS solution with different concentrations of Sr and Si were prepared, see Table 1.

The heat-treated titanium plates were placed in sealed plastic bottles containing $\mathrm{Sr}-\mathrm{Si}$-PBS solutions at $37^{\circ} \mathrm{C}$ or $60^{\circ} \mathrm{C}$ for 2 weeks. The solution was exchanged after 1 week to avoid significant ion depletion in the solution. After completed soaking, the plates were gently rinsed in deionised water and dried at $37^{\circ} \mathrm{C}$ before further analysis.

\subsection{Characterization of Sr and Si Co-Doped Apatite Coatings}

The coatings were analyzed by X-ray diffraction (XRD) (Siemens diffractometer D5000). The diffractometer was operated at $45 \mathrm{kV}$ and $40 \mathrm{~mA}$ at a $2 \theta$ range of $20^{\circ}$ $60^{\circ}$. The incidence angle was fixed at $2^{\circ}$.

The morphology of the coatings was investigated using field emission scanning electron microscopy (FESEM, LEO1550). Before the SEM analysis, the samples were coated with a thin film of gold, using ion sputtering. SEM images were acquired at different magnifications, using the in-lens detector and an acceleration voltage of 3 $\mathrm{kV}$. Inductively coupled plasma-optical emission spectroscopy (ICP-OES) was used for analyzing the composition and the ion release from the co-doped $\mathrm{Sr}$ and $\mathrm{Si}$ apatite coating (see below).

\subsection{Ion Release from $\mathrm{Sr}$ and $\mathrm{Si}$ Co-Doped Apatite Coatings}

In order to study the stability and ion release characteristics, the release of $\mathrm{Sr}$ and $\mathrm{Si}$ ions into solutions of Tris- $\mathrm{HCl}$ and PBS was measured for one selected coating, 015Sr2Si-PBS prepared at $60^{\circ} \mathrm{C}$ for 2 weeks. This selected coating has the highest $\mathrm{Sr} / \mathrm{Ca}$ and $\mathrm{Si} / \mathrm{P}$ ratios according to ICP-OES analysis. The Sr and Si containing apatite coating was prepared as described above, with the exception that the PBS solution was exchanged every 3 days. The coated samples were immersed in $10 \mathrm{~mL}$ of Tris-HCl or PBS solution (5 mL/plate), in closed plastic bottles, for periods up to 14 days. The ion release experiment was performed in static mode using the following protocol. At time points 3 hours, 1 day, 3 days, 5 days, 8 days and 14 days, $2 \mathrm{~mL}$ solution was withdrawn from the solution and stored in centrifuge tubes prior to analysis by ICP-OES. $2 \mathrm{~mL}$ fresh solution was added to maintain a constant volume of solution.

\subsection{Mechanism of Ion Release from the Coatings}

Korsmeyer-Peppas model (Equation (1)):

$$
F=\frac{Q_{t}}{Q}=k t^{n}
$$

was used to analyse the measured ion release data in order to evaluate the mechanism of release from the codoped $\mathrm{Sr}$ and $\mathrm{Si}$ apatite coatings. In this model, $F$ is the fraction of ion release after time $t, Q_{t}$ is the amount of

Table 1. Ion concentration in Dulbecco's PBS and Sr-Si-PBS $\left(10^{-3} \mathrm{M}\right)$.

\begin{tabular}{|c|c|c|c|c|c|c|c|c|}
\hline Ion (mmol/l) & $\mathrm{Na}^{+}$ & $\mathrm{K}^{+}$ & $\mathrm{Mg}^{2+}$ & $\mathrm{Ca}^{2+}$ & $\mathrm{Cl}^{-}$ & $\mathrm{HPO}_{4}^{2-}$ & $\mathrm{Sr}^{2+}$ & $\mathrm{SiO}_{3}^{2-}$ \\
\hline Blood plasma & 142.0 & 5.0 & 1.5 & 2.5 & 103.0 & 1.0 & & \\
\hline PBS & 145.0 & 4.2 & 0.49 & 0.91 & 143 & 9.6 & & \\
\hline $006 \mathrm{Sr}+1 \mathrm{Si}-\mathrm{PBS}$ & 145.0 & 4.2 & 0.49 & 0.91 & 143 & 9.6 & 0.06 & 1 \\
\hline 015Sr + 1Si-PBS & 145.0 & 4.2 & 0.49 & 0.91 & 143 & 9.6 & 0.15 & 1 \\
\hline 006Sr + 2Si-PBS & 145.0 & 4.2 & 0.49 & 0.91 & 143 & 9.6 & 0.06 & 2 \\
\hline $015 \mathrm{Sr}+2 \mathrm{Si}-\mathrm{PBS}$ & 145.0 & 4.2 & 0.49 & 0.91 & 143 & 9.6 & 0.15 & 2 \\
\hline
\end{tabular}


substance released after time $t, Q$ is the total amount of substance, $k$ is the kinetic constant, $n$ the diffusion release constant which is characteristic of the release mechanism and $t$ is the time in hours [21]. Using this model different ion kinetic values $(n)$ were calculated. To evaluate the release mechanism an $n$ value of 0.5 was used. We assume that the apatite particles are plate-like, and according to the paper by Ritger and Peppas [19], Fickian diffusion has a limited value of $n=0.5$ for slabs. Values of $n<0.5$ means the release is controlled mainly by a quasi-Fickian diffusion mechanism. If the $n$ value is between 0.5 and 1 the release of ions from the coatings is a combination of Fickian diffusion and dissolution of the coating [22]. These values can be used to assess which mechanism is controlling the release of ions from the co-doped $\mathrm{Sr}$ and Si apatite coating.

\section{Results}

\subsection{SEM Analysis}

The morphology of samples formed in the different solutions at a given temperature show similar morphologies, see Figures 1 and 2.

However, the coatings formed at different tempera-
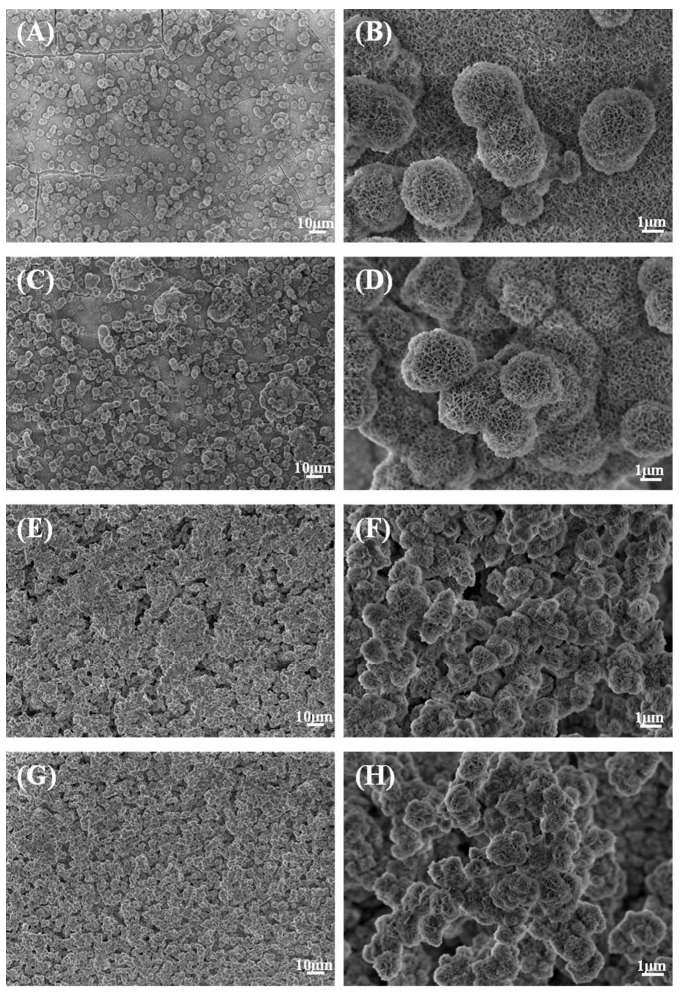

Figure 1. Morphology of the $\mathrm{Sr}$ and $\mathrm{Si}$ co-doped apatite coatings. The heat treated surfaces were soaked for 2 weeks with: (A) and (B) $0.06 \mathrm{mM} \mathrm{Sr}$ and $1 \mathrm{mM} \mathrm{Si}$ at $37^{\circ} \mathrm{C}$; (C) and (D) $0.15 \mathrm{mM} \mathrm{Sr}$ and $1 \mathrm{mM} \mathrm{Si}$ at $37^{\circ} \mathrm{C}$; (E) and (F) $0.06 \mathrm{mM}$ $\mathrm{Sr}$ and $1 \mathrm{mM} \mathrm{Si-PBS}$ at $60^{\circ} \mathrm{C}$; (G) and (H) $0.15 \mathrm{mM} \mathrm{Sr}$ and $1 \mathrm{mM} \mathrm{Si}$ at $60^{\circ} \mathrm{C}$.
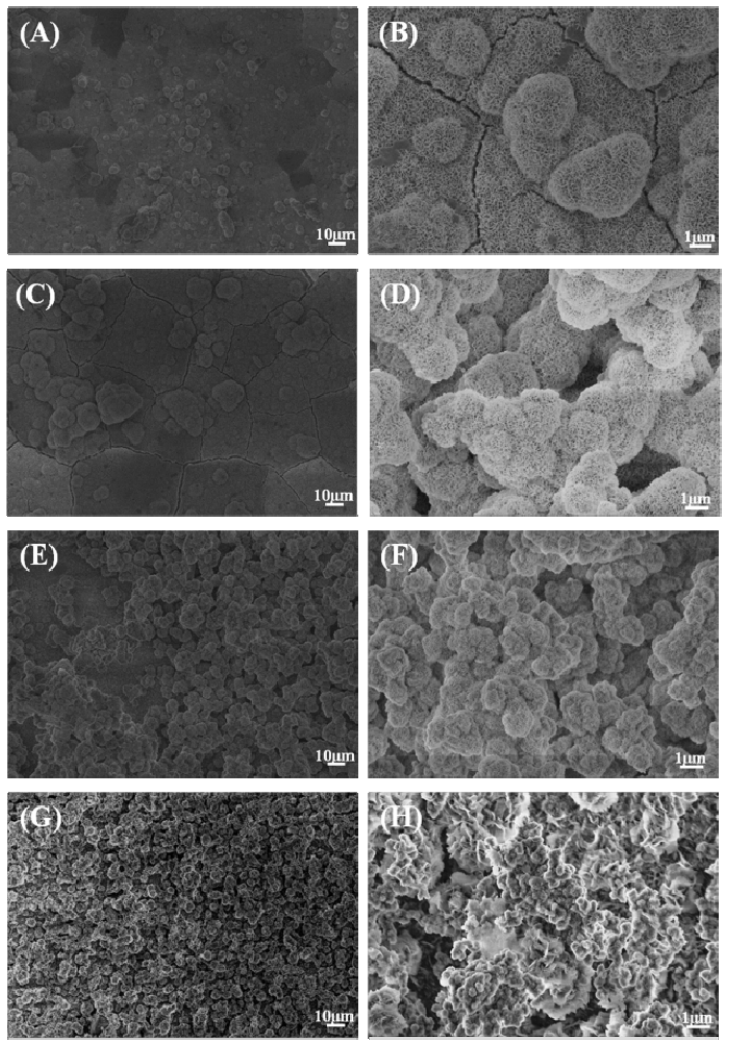

Figure 2. Morphology of the Sr and Si co-doped apatite coatings. The heat treated surfaces were soaked for 2 weeks with: (A) and (B) $0.06 \mathrm{mM} \mathrm{Sr}$ and $2 \mathrm{mM} \mathrm{Si}$ at $37^{\circ} \mathrm{C}$; (C) and (D) $0.15 \mathrm{mM} \mathrm{Sr}$ and $2 \mathrm{mM} \mathrm{Si}$ at $37^{\circ} \mathrm{C}$; (E) and (F) $0.06 \mathrm{mM}$ Sr and $2 \mathrm{mM} \mathrm{Si-PBS}$ at $60^{\circ} \mathrm{C}$; (G) and (H) $0.15 \mathrm{mM} \mathrm{Sr}$ and $2 \mathrm{mM} \mathrm{Si}$ at $60^{\circ} \mathrm{C}$.

tures showed clear differences. Coatings formed at $37^{\circ} \mathrm{C}$ show an underlying relative uniform coating, which was partially covered by the sphere-like particles (typical size $3-5 \mu \mathrm{m})$. Both the underlying layer and the spheres had flake-like morphology in the submicron scale. For the coatings formed at $60^{\circ} \mathrm{C}$, the morphology was completely dominated by partially fused or interlocked sphere-like particles. The size of the particles was typically $1-2 \mu \mathrm{m}$. The size of the particles was larger for the coatings prepared at $37^{\circ} \mathrm{C}$ compared to those at $60^{\circ} \mathrm{C}$, see Figures 1 and 2.

\subsection{X-Ray Diffraction (XRD) Analysis}

All the co-doped Sr and Si apatite coatings showed peaks of apatite (hydroxyapatite, PDF No. 09-0432) after soaking at $37^{\circ} \mathrm{C}$ and $60^{\circ} \mathrm{C}$ for 2 weeks, see Figure 3 .

The peak at around $26^{\circ}$ is related to plane (002). The peak at around $31^{\circ}$ was broad and could be the overlapping of the planes (211), (112), (300). In addition two peaks were detected around $46^{\circ}$ which corresponds to plane (222) and $49^{\circ}$ which was related to plane (213). The relatively broad apatite peaks indicate that the 

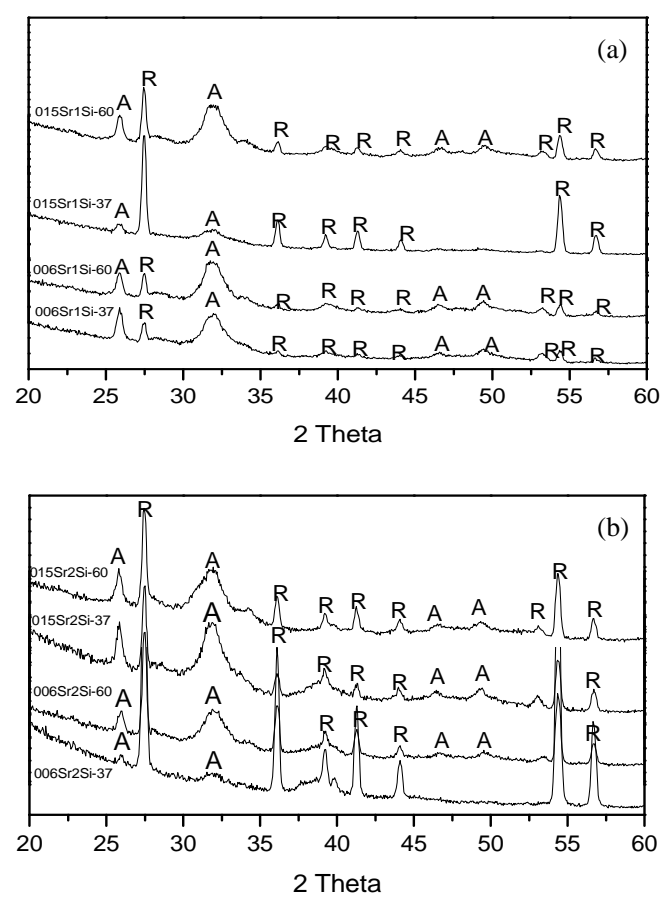

Figure 3. XRD patterns of coatings prepared for 2 weeks in D-PBS with different concentrations and soaking temperature: (a) 2 mM Si; (b) 1 mM Si (R: rutile; A: apatite).

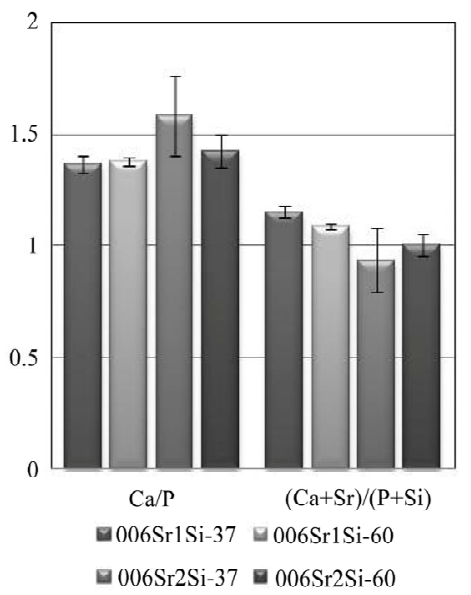

(a)

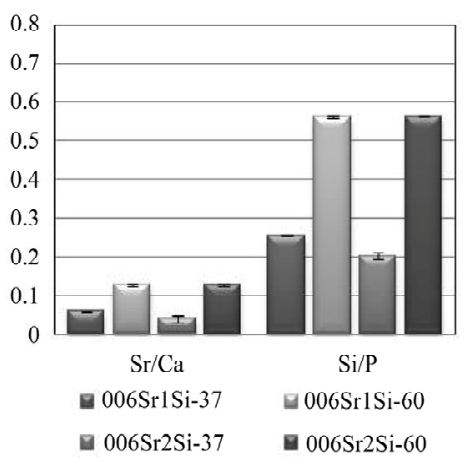

(c) coating were poorly crystalline. It can also be observed that the intensity of peaks corresponding to apatite were stronger at $60^{\circ} \mathrm{C}$ than $37^{\circ} \mathrm{C}$, most likely this was due to higher thickness.

\subsection{ICP-OES Analysis}

In the ICP-OES analysis, $\mathrm{Ca}, \mathrm{Mg}, \mathrm{P}, \mathrm{Sr}$ and Si were detected in all coatings. The $\mathrm{Ca} / \mathrm{P}$ and $(\mathrm{Ca}+\mathrm{Sr}) /(\mathrm{Si}+\mathrm{P})$ ratios were between $1.2-1.4$ and $1.1-1.2$, respectively (Figures 4(a) and (b)).

These ratios are much lower than for stoichiometric HA, 1.67 which indicates that the coatings are calcium deficient. This is also in agreement with previous results on single ion co-doped calcium phosphate films [16]. It can be observed that there was a difference between the $\mathrm{Ca} / \mathrm{P}$ ratio and the $(\mathrm{Ca}+\mathrm{Sr}) /(\mathrm{Si}+\mathrm{P})$ ratios; taking into account of the addition of $\mathrm{Sr}$ and $\mathrm{Si}$ ions decreased the ratio somewhat (see Figures 4(a) and (b)). The soaking temperature and ion concentrations of $\mathrm{Sr}$ and $\mathrm{Si}$ in the solution did not significantly affect the $\mathrm{Ca} / \mathrm{P}$ or the $(\mathrm{Ca}+$ $\mathrm{Sr}) /(\mathrm{Si}+\mathrm{P})$ ratios. However the $\mathrm{Sr} / \mathrm{Ca}$ ratios showed an increase with increasing $\mathrm{Sr}$ concentration in the medium and with increasing soaking temperature, see Figures 4(c) and (d). The same trend was observed for the Si/P ratio.

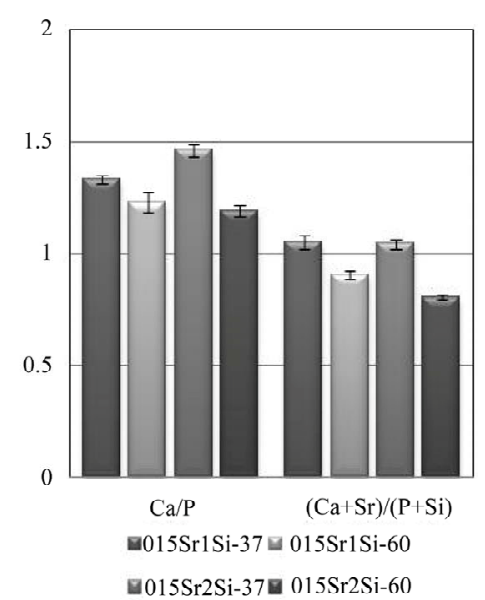

(b)

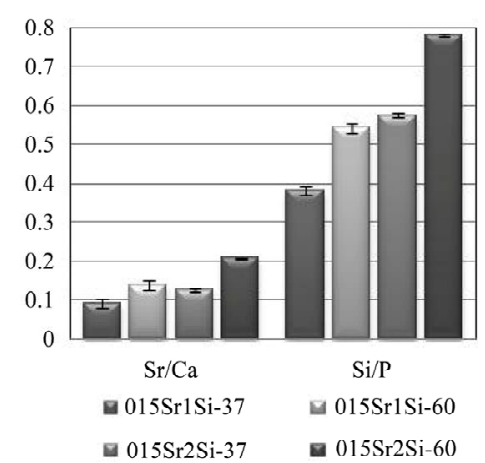

(d)

Figure 4. (a), (b): $\mathrm{Ca} / \mathrm{P}$ and $(\mathrm{Ca}+\mathrm{Sr}) /(\mathrm{Si}+\mathrm{P})$ ratios; (c), (d): $\mathrm{Sr} / \mathrm{Ca}$ and $\mathrm{Si} / \mathrm{P}$ ratios for $\mathrm{SrSiHA}$ obtained by ICP-OES analysis. 
The Si/P ratios were higher than the Sr/Ca indicating that the silicon content in the coating was higher than that of Sr.

\subsection{Ion Release}

The ion release results show that it was possible to release both $\mathrm{Sr}$ and $\mathrm{Si}$ from the co-doped $\mathrm{Sr}$ and $\mathrm{Si}$ apatite coating. The ICP analyses revealed that release of $\mathrm{Ca}$, $\mathrm{Mg}, \mathrm{Sr}$ and Si occurred in both PBS and Tris-HCl. The release profiles (ion concentration in solution vs. immersion time) were different in Tris- $\mathrm{HCl}$ compared to the PBS solution that contains $\mathrm{Ca}$ and $\mathrm{Mg}$ ions, see Figures 5(a) and (b).

In Tris-HCl there was a continuous sustained release of $\mathrm{Ca}, \mathrm{Mg}, \mathrm{Sr}$ and Si. The release of Si was higher than the release of Sr. SEM images, Figure 5, of the co-substituted $\mathrm{Sr}$ and $\mathrm{Si}$ apatite coating before and after release in Tris-HCl showed similar morphology.

In PBS there was an initial drop observed during the first $24 \mathrm{~h}$, after which the Ca concentration slowly increased and the stabilized. For Mg there was a slow decrease indicating precipitation. Both $\mathrm{Sr}$ and Si showed a continuous sustained release. The release of Si was higher than for Sr in PBS. After ion release in PBS newly

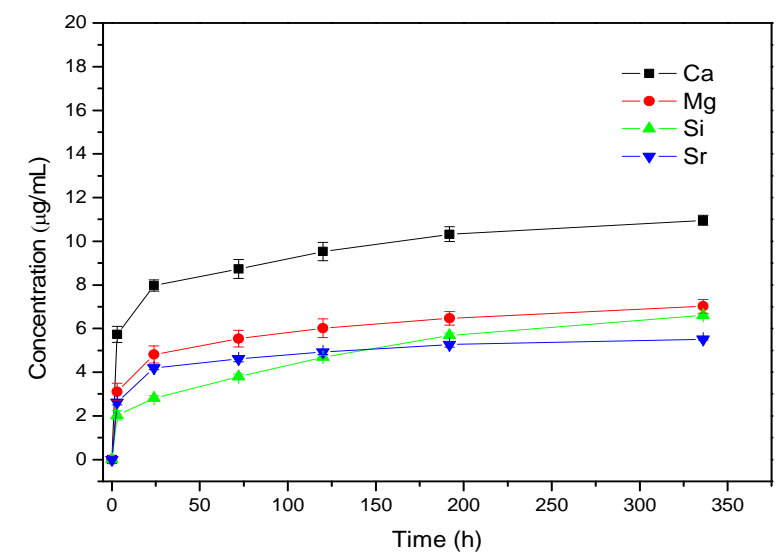

(a)

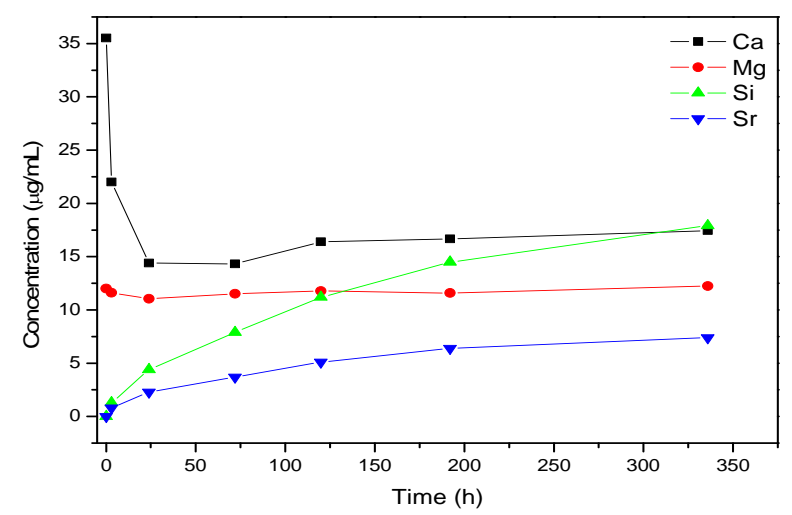

(b)

Figure 5. Ion release curves for $015 \mathrm{Sr} 2 \mathrm{SiHA}$ coating in (a) Tris-HCl and (b) PBS.
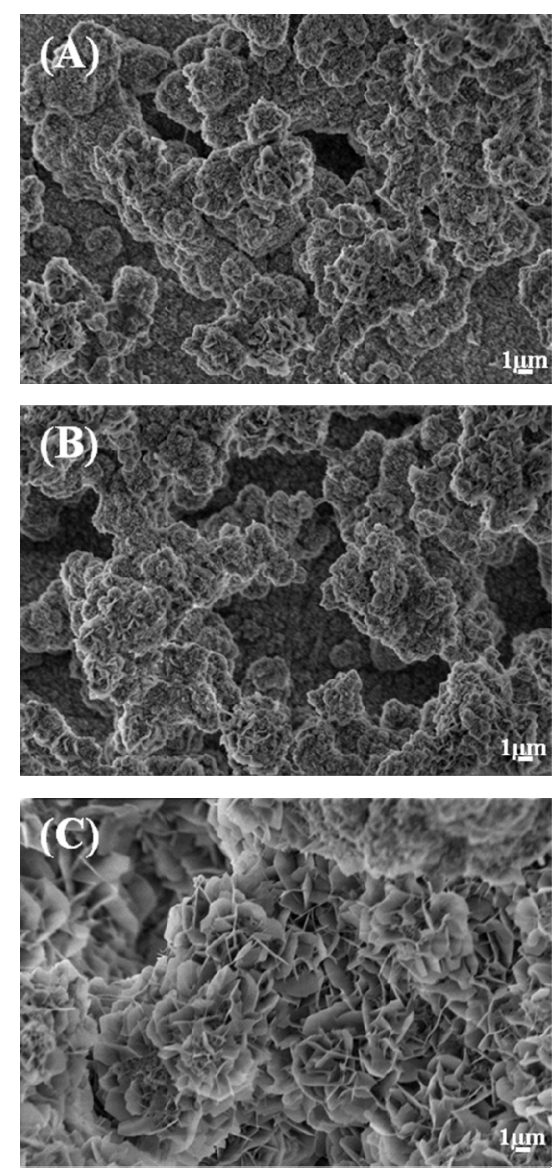

Figure 6. Morphology of 015Sr2SiHA coating before release (A), and after ion release in Tris-HCl (B) and PBS (C).

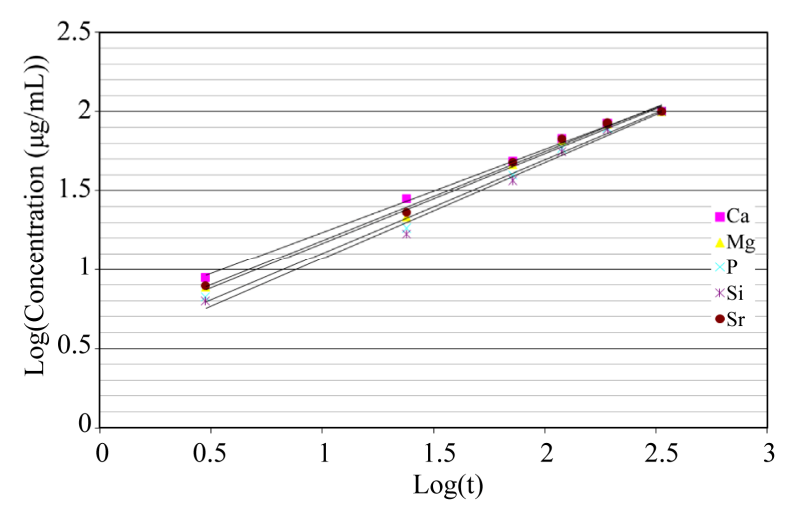

Figure 7. Korsmeyer-peppas plot for 015Sr2SiHA after ion release in Tris-HCl.

formed apatite was observed on the surface, Figure 6.

Figure 7 shows Korsmeyer-Peppas plots for the release data. The ion kinetic values $(n)$, summarized in Table 2, showed that the release of ions in Tris- $\mathrm{HCl}(n \mathrm{Ca}$ $=0.53, n \mathrm{Mg}=0.57, n \mathrm{P}=0.60, n \mathrm{Sr}=0.56, n \mathrm{Si}=0.61$ ) were a combination of Fickian diffusion and dissolution of the coatings. The obtained $\mathrm{R}^{2}$ values $>0.98$ show that the K-P model fits well for describing the ion release 
Table 2. Ion release kinetic values in Tris-HCl for co-substituted $\mathrm{Sr}$ and Si apatite coating.

\begin{tabular}{ccc}
\hline Ions & $n$ & $\mathrm{R}$ \\
\hline $\mathrm{Ca}^{2+}$ & 0.53 & 0.99 \\
$\mathrm{Mg}^{2+}$ & 0.57 & 0.99 \\
$\mathrm{P}$ & 0.60 & 0.99 \\
$\mathrm{Sr}^{2+}$ & 0.56 & 0.99 \\
$\mathrm{Si}^{4+}$ & 0.61 & 0.99 \\
\hline
\end{tabular}

from co-doped apatite HA coatings.

\section{Discussion}

This study shows that it was possible to prepare apatite coatings containing both $\mathrm{Sr}$ and $\mathrm{Si}$ ions. The overall morphology of the Sr and Si co-doped apatite coatings is consisted of micron-sized particles with a plate-like structure on the submicron scale, similar to those earlier observed for pure apatite coatings prepared with a similar technique [23]. In the paper published previously by Xia et al., it was shown the morphology changed dramatically when incorporating $\mathrm{Sr}$ ion into the apatite coating [18]. However, when Si was incorporated, the morphology was similar to that of pure HA [19]. In this study, however, simultaneous incorporation of both $\mathrm{Sr}$ and $\mathrm{Si}$ resulted in a morphology that was similar to pure HA prepared by the same immersion method. ICP-OES analysis also indicated that the Sr content in the coating was lower than that of silicon which could explain why the coating in this study was similar to pure HA.

The soaking method used in this study has previously been shown to give an apatite coating that is calcium deficient and with poor crystallinity [24-26]. The Ca/P ratios for all coatings prepared with different soaking temperatures and with different ion concentrations of $\mathrm{Sr}$ and Si ions in the solution were below that for stochiometric hydroxyapatite, i.e. calcium deficient. The broad peaks corresponding to apatite observed in the XRD results indicated that also these co-doped coatings are poorly crystalline. In addition the XRD data showed that the peaks corresponding to apatite were stronger at $60^{\circ} \mathrm{C}$ compared to $37^{\circ} \mathrm{C}$, indicating that increasing the soaking temperature result in a thicker and possibly also more crystalline coating.

In addition, a higher soaking temperature and higher $\mathrm{Sr}$ ion concentration also resulted in a more Sr rich coating, in agreement with previous studies by Xia et al. [18]. A significant difference in Si content was observed between different coatings prepared at different temperatures. Taking into account the doping, the calculated (Ca $+\mathrm{Sr}) /(\mathrm{Si}+\mathrm{P})$ ratios were found to be typically $20 \%$ lower than the corresponding $\mathrm{Ca} / \mathrm{P}$ ratios, taken as an indication that that the $\mathrm{Si}$ content in the coating is higher than that of $\mathrm{Sr}$.

The results from the ion release experiments showed that it was possible to release $\mathrm{Sr}$ and $\mathrm{Si}$ simultaneously from the coatings, which could combine the dual effect of these ions on bone tissue regeneration in vivo. The effects of these co-doped apatite coatings on bone healing remains to be demonstrated by in vivo experiments. As mentioned in the introduction, a coating with low crystallinity may be beneficial for the osteoconductivity [27]. A coating may also act as a local delivery system of $\mathrm{Sr}$ and $\mathrm{Si}$ ions, combining the beneficial effects of these ion species. In addition, model analyses using the Korsmeyer-Peppas model show $n$ values that are between 0.5 and 1 , which indicates that the release of ions from the coating is a combination of Fickian diffusion and dissolution of the coating. In the future the cell and bone response to these co-doped $\mathrm{Sr}$ and $\mathrm{Si}$ apatite coatings would be interesting to study.

\section{Conclusion}

In this study, co-doped Sr and Si apatite coatings were prepared via a solution method. The coatings were poorly crystalline, and the $\mathrm{Ca} / \mathrm{P}$ ratios were lower than that of stoichiometric hydroxyapatite. The increased temperature and ion concentration of the solutions increased the amount of strontium and silicon ions in apatite coatings. The release rate of $\mathrm{Sr}$ and $\mathrm{Si}$ ions from the coatings was faster in Tris-HCl than in PBS, and was for both ions controlled by a combination of Fickian diffusion and dissolution of the coating. In PBS, re-precipitation of apatite occurred in parallel with the ion release. The release results show that this type of coatings could be used as a vehicle for delivery of biologically active ions.

\section{Acknowledgements}

This work was supported by BIOMATCELL, VINN Excellence Center of Biomaterials and Cell Therapy. Emma Fransson (SP) is gratefully acknowledged for performing ICP analysis. We also thank Cecilia Persson for proof reading the manuscript.

\section{REFERENCES}

[1] B. Chou and E. Chang, "Microstructural Characterization of Plasma-Sprayed Hydroxyapatite-10 wt $\% \mathrm{ZrO}_{2}$ Composite Coating on Titanium,” Biomaterials, Vol. 20, No. 19, 1999, pp. 1823-1832. doi:10.1016/S0142-9612(99)00078-2

[2] A. Hideki, "Science and Medical Applications of Hydroxyapatite,” Ishiyaku Euroamerica, St. Louis, 1992.

[3] K. Degroot, R. Geesink, C. Klein and P. Serekain, "Plasma Sprayed Coatings of Hydroxyapatite," Journal of Biomedical Materials Research, Vol. 21, No. 12, 1992, pp. 1375-1381. doi:10.1002/jbm.820211203 
[4] W. Jaffe and D. Scott, "Total Hip Arthroplasty with Hydroxyapatite-Coated Prosthesis,” Journal of Bone and Joint Surgery, Vol. 78, No. 12, 1996, pp. 1918-1934.

[5] J. Forsgren, U. Brohede and M Strømme, “Co-Loading of Bisphosphonates and Antibiotics to a Biomimetic Hydroxyapatite Coating," Biotechnology Letters, Vol. 33, No. 6, 2011, pp. 1265-1268. doi:10.1007/s10529-011-0542-7

[6] M. Vallet-Regi and D. Arcos, "Silicon Substituted Hydroxyapatites. A Method to Upgrade Calcium Phosphate Based Implants," Materials Chemistry, Vol. 15, 2005, pp. 1509-1516. doi:10.1039/b414143a

[7] A. Oliveira, R. Reis and P. Li," Strontium-Substituted Apatite Coating Grown on Ti6Al4V Substrate through Biomimetic Synthesis,” Journal of Biomedical Materials Research Part B, Vol. 83, 2007, pp. 258-265.

[8] S. Cazalbou, C. Combes and C. Rey, "Biomimetic Approach for Strontium Containing Ca-P Bioceramics with Enhanced Biological Activity,” Key Engineering Materials, Vol. 192, 2001, pp. 192-195.

[9] I. Gibson, S. Best and W. Bonfield, "Chemical Characterization of Silicon-Substituted Hydroxyapatite,” Journal of Biomedical Materials Research, Vol. 44, No. 6, 1999, pp. 422-428.

doi:10.1002/(SICI)1097-4636(19990315)44:4<422::AIDJBM8>3.0.CO;2-\#

[10] M. Vallet-Regi and J. M. Gonzalez-Calbet, "Calcium Phosphates as Substitution of Bone Tissues," Progress in Solid State Chemistry, Vol. 32, No. 1-2, 2004, pp. 1-31. doi:10.1016/j.progsolidstchem.2004.07.001

[11] S. V. Dorozhkin and M. Epple, "Biological and Medical Significance of Calcium Phosphates," Angewandte Chemie International Edition, Vol. 41, No. 17, 2002, pp. 3130-3146. doi:10.1002/1521-3773(20020902)41:17<3130::AID-AN $\underline{\text { IE3130>3.0.CO;2-1 }}$

[12] P. Marie, P. Ammann, G. Boivin and C. Rey, "Mechanisms of Action and Therapeutic Potential of Strontium in Bone," Calcified Tissue International, Vol. 69, No. 3, 2001, pp. 121-129. doi:10.1007/s002230010055

[13] E. Zhang and C. Zou, "Porous Titanium and SiliconSubstituted Hydroxyapatite Biomodification Prepared by a Biomimetic Process: Characterization and in Vivo Evaluation," Acta Biomaterialia, Vol. 5, No. 5, 2009, pp. 1732-1741. doi:10.1016/j.actbio.2009.01.014

[14] S. Kannan, A. Rebelo and J. M. F. Ferreira, "Novel Synthesis and Structural Characterization of Fluorine and Chlorine Co-Substituted Hydroxyapatites,” Journal of Inorganic Biochemistry, Vol. 100, No. 10, 2006, pp. 16921697. doi:10.1016/j.jinorgbio.2006.06.005

[15] S. Kannan, J. H. G. Rocha and J. M. F. Ferreira, "Synthesis and Thermal Stability of Sodium, Magnesium CoSubstituted Hydroxyapatites," Journal of Materials Chemistry, Vol. 16, No. 3, 2006, pp. 286-291. doi:10.1039/b511867k

[16] E. Landi, S. Sprio, M. Sandri, G. Celotti and A. Tampieri, "Development of $\mathrm{Sr}$ and $\mathrm{CO}_{3}$ Co-Substituted Hydroxyapatites for Biomedical Applications,” Acta Biomaterialia,
Vol. 4, No. 3, 2008, pp. 656-663. doi:10.1016/j.actbio.2007.10.010

[17] I. Gibson and W. Bonfield, "Preparation and Characterization of Magnesium/Carbonate Co-Substituted Hydroxyapatites," Journal of Materials Science: Materials in Medicine, Vol. 13, No. 7, 2002, pp. 685-693. doi:10.1023/A:1015793927364

[18] W. Xia, C. Lindahl, J. Lausmaa, P. Borchardt, A. Ballo, P. Thomsen and H. Engqvist, "Biomineralized StrontiumSubstituted Apatite/Titanium Dioxide Coating on Titanium Surfaces,” Acta Biomaterialia, Vol. 6, No. 4, 2010, pp. 1591-1600. doi:10.1016/j.actbio.2009.10.030

[19] W. Xia, C. Lindahl, C. Persson, P. Thomsen, J. Lausmaa and H. Engqvist, "Changes of Surface Composition and Morphology after Incorporation of Ions into Biomimetic Apatite Coating," Journal of Biomaterials and Nanobiotechnology, Vol. 1, 2010, pp. 7-16. doi:10.4236/jbnb.2010.11002

[20] E. Zhang, C. Zou and S. Zeng, "Preparation and Characterization of Silicon-Substituted Hydroxyapatite Coating by a Biomimetic Process on Titanium Substrate," Surface and Coatings Technology, Vol. 203, No. 8, 2009, pp. 1075-1080. doi:10.1016/j.surfcoat.2008.09.038

[21] P. Ritger and N. Peppas, "A Simple Equation for Description of Solute Release I. Fickian and Non-Fickian Release from Non-Swellable Devices in the Form of Slabs, Spheres, Cylinders or Discs,” Journal of Controlled Release, Vol. 5, No. 1, 1987, pp. 23-36. doi:10.1016/0168-3659(87)90034-4

[22] N. Peppas, “Analysis of Fickian and Non-Fickian Drug Release from Polymers,” Pharmaceutica Acta Helvetiae, Vol. 60, 1985, pp. 110-111.

[23] M. Lindgren, M. Astrand, U. Wiklund and H. Engqvist, "Investigation of Boundary Conditions for Biomimetic HA Deposition on Titanium Oxide Surfaces,” Journal of Materials Science: Materials in Medicine, Vol. 20, No. 7, 2009, pp. 1401-1408. doi:10.1007/s10856-009-3709-1

[24] J. E. Ellingsen and S. P. Lyngstadaas, "Bio-Implant Interface: Improving Biomaterials and Tissue Reactions" CRC Press, 2003. doi:10.1201/9780203491430

[25] H. B. Wen, J. R. D. Wijin, F. Z. Cui and K. D. Groot, "Preparation of Calcium Phosphate Coatings on Titanium Implant Materials by Simple Chemistry," The Journal of Biomedical Materials Research, Vol. 41, No. 2, 1998, pp. 227-236.

doi:10.1002/(SICI)1097-4636(199808)41:2<227::AID-JB M7>3.0.CO;2-K

[26] J. Forsgren, F. Svahn, T. Jarmar and H. Engqvist, "Formation and Adhesion of Biomimetic Hydroxyapatite Deposited on Titanium Substrates," Acta Biomaterialia, Vol. 3, No. 6, 2007, pp. 980-984. doi:10.1016/j.actbio.2007.03.006

[27] A. E. Porter, N. Patel, J. N. Skepper, S. M. Best and W. Bonfield, "Comparison of in Vivo Dissolution Processes in Hydroxyapatite and Silicon-Substituted Hydroxyapatite Bioceramics,” Biomaterials, Vol. 24, No. 25, 2003, pp. 4609-4620. doi:10.1016/S0142-9612(03)00355-7 